\title{
Phenotype heterogeneity of congenital adrenal hyperplasia due to genetic mosaicism and concomitant nephrogenic diabetes insipidus in a sibling
}

\author{
Yılmaz Kor ${ }^{1 \dagger}$, Minjing Zou ${ }^{2 \dagger}$, Roua A. Al-Rijjal², Dorota Monies², Brian F. Meyer ${ }^{2}$ and Yufei Shi ${ }^{2 *}$ (D
}

\begin{abstract}
Background: Congenital adrenal hyperplasia (CAH) due to 21-hydroxylase deficiency (21OHD) is an autosomal recessive disorder caused by mutations in the CYP21A2. Congenital nephrogenic diabetes insipidus (NDI) is a rare Xlinked recessive or autosomal recessive disorder caused by mutations in either AVPR2 or AQP2. Genotype-phenotype discordance caused by genetic mosaicism in CAH patients has not been reported, nor the concomitant CAH and NDI.

Case presentation: We investigated a patient with concomitant CAH and NDI from a consanguineous family. She (S1) presented with clitoromegaly at 3 month of age, and polydipsia and polyuria at 13 month of age. Her parents and two elder sisters (S-2 and S-3) were clinically normal, but elevated levels of serum 17-hydroxyprogesterone (17-OHP) were observed in the mother and S-2. The coding region of CYP21A2 and AQP2 were analyzed by PCR-sequencing analysis to identify genetic defects. Two homozygous CYP21A2 mutations (p.R357W and p.P454S) were identified in the proband and her mother and S-2. The apparent genotype-phenotype discordance was due to presence of small amount of wild-type CYP21A2 alleles in S-1, S-2, and their mother's genome, thus protecting them from development of classic form of 21OHD (C21OHD). A homozygous AQP2 mutation (p.A147T) was also found in the patient. The patient was treated with hydrocortisone and hydrochlorothiazide. Her symptoms were improved with normal laboratory findings. The clitoromegaly is persisted.
\end{abstract}

Conclusions: Genetic mosaicism is a novel mechanism contributing to the genotype-phenotype discordance in $21 \mathrm{OHD}$ and small percentage of wild-type CYP21A2 alleles may be sufficient to prevent phenotype development. This is a first report of concurrent 21OHD and NDI caused by simultaneous homozygous CYP21A2 and AQP2 mutations.

Keywords: 21-hydroxylase deficiency, Mosaicism, Nephrogenic diabetes insipidus, CYP21A2, AQP2

\section{Background}

Congenital adrenal hyperplasia (CAH) is a group of autosomal recessive disorders of steroid metabolism caused by the deficiency (loss of or severely decreased activity) of one of five steroidogenic enzymes involved in the cortisol biosynthesis: cholesterol side-chain cleavage enzyme (CYP11A1), 3 beta-hydroxysteroid dehydrogenase (HSD3B2), 17 alpha-hydroxylase/17,20 lyase (CYP17A1), 21-hydroxylase (CYP21A2), and 11 beta-hydroxylase

\footnotetext{
* Correspondence: yufei@kfshrc.edu.sa

†YIImaz Kor and Minjing Zou contributed equally to this work.

${ }^{2}$ Department of Genetics (MBC-03), King Faisal Specialist Hospital and

Research Centre, P.O. Box 3354, Riyadh 11211, Saudi Arabia

Full list of author information is available at the end of the article
}

(CYP11B1) [1]. More than 95\% of CAH cases are from steroid 21-hydroxylase deficiency (21OHD, MIN 201910) due to mutations in the CYP21A2 gene [2-4].

Steroid 21-hydroxylase catalyzes the conversion of 17-hydroxyprogesterone (17-OHP) to 11-deoxycortisol, and progesterone to 11-deoxycorticosterone. Its deficiency leads to overproduction and accumulation of 17-OHP. This results in excessive androgen production and decreased aldosterone and cortisol synthesis. Based on the clinical severity, $\mathrm{CAH}$ can be classified into classic form of 21OHD (C21OHD) and the mild non-classic form of 21OHD (NC21OHD). C21OHD is estimated to occur with a frequency of 1 in 7000 to 15,000 live births in most

(c) The Author(s). 2018 Open Access This article is distributed under the terms of the Creative Commons Attribution 4.0 International License (http://creativecommons.org/licenses/by/4.0/), which permits unrestricted use, distribution, and reproduction in any medium, provided you give appropriate credit to the original author(s) and the source, provide a link to the Creative Commons license, and indicate if changes were made. The Creative Commons Public Domain Dedication waiver (http://creativecommons.org/publicdomain/zero/1.0/) applies to the data made available in this article, unless otherwise stated. 
populations and can be further divided into salt-wasting $(70 \%)$ and simple virilizing form $(30 \%)$ [3, 5]. The salt-wasting form is characterized by severe renal salt loss as a consequence of aldosterone deficiency whereas the simple virilizing form is characterized by virilization of external genitalia (clitoromegaly in females and penile growth in males) and precocious pseudopuberty as a result of adrenal androgen overproduction. NC21OHD occurs approximately in a frequency of 1 in 1000 live births in various Caucasian populations and is predominantly in female patients with pseudopuberty, acne, hirsutism, and decreased fertility [5]. It is often discovered during studies of family members who have classic form of the disease. In contrast to C21OHD, it is generally believed that patients with NC21OHD have mild mutations on both alleles or one severe and one mild mutations of CYP21A2 that retain some of 21-hydroxylase activity. For example, missense mutations in exon 1 (P30L), exon 7 (V281 L), exon $8(\mathrm{R} 339 \mathrm{H})$, or exon 10 (P454S) are found in NC21OHD patients with enzymatic activity of about 20 $60 \%$ of wild-type [6]. Although there is a strong genotype-phenotype correlation in $80-90 \%$ of cases [4, 7], discordance can still be found in remaining patients $[8,9]$.

Diabetes insipidus is defined as the passage of large volumes $\left(>3 \mathrm{~L} / 24 \mathrm{~h}\right.$ or $2 \mathrm{~L} / \mathrm{m}^{2} / 24 \mathrm{~h}$ ) of dilute urine with reduced urine osmolality $(<300 \mathrm{mOsm} / \mathrm{kg})$ and is caused by reduced or absent secretion of pituitary antidiuretic hormone arginine vasopressin or by a poor kidney response to the hormone. Polyuria with hyposthenuria and polydipsia are the main hallmarks of the disease. Congenital nephrogenic diabetes insipidus (NDI) is a rare genetic disorder of kidney characterized by a defect to concentrate urine despite normal or elevated arginine vasopressin [10]. About $90 \%$ of patients are males with X-linked recessive
NDI (OMIM 304800) caused by mutations in the arginine-vasopressin receptor 2 gene (AVPR2). In $10 \%$ of patients, the disease is caused by mutations in the aquaporin-2 gene (AQP2) and transmitted as an autosomal-recessive or autosomal-dominant (OMIM 125800) mode [11-13].

In the present study, we characterized a family with concomitant NC21OHD and NDI, and identified genetic mosaicism as a new mechanism causing phenotype heterogeneity of $21 \mathrm{OHD}$.

\section{Case presentation}

The proband (S-1 in Table 1) was first admitted to the hospital due to clitoromegaly at 3 months of age. She was born with normal vaginal delivery at 39 weeks of pregnancy, and weighed $3500 \mathrm{~g}$. She was a third child of consanguineous parents who are first-degree cousins. Her mother had a history of menstrual irregularity and mild hirsutism, and was diagnosed polycystic ovary syndrome at a different hospital. Her two elder sisters were normal with regular menstrual cycle and breast development Tanner stage IV, axillary and pubic hair Tanner stage V. Physical examination showed clitoromegaly $(1.5 \mathrm{~cm})$ without urogenital sinus and hyperpigmentation. Laboratory tests showed elevated 17-OHP $(6.3 \mathrm{ng} / \mathrm{ml}$, normal 0.2-0.9 ng/ $\mathrm{ml})$, normal ACTH $(10 \mathrm{pg} / \mathrm{ml}$, normal: $10-60 \mathrm{pg} / \mathrm{ml})$ and cortisol $9.6 \mu \mathrm{g} / \mathrm{dl}$ (normal: $6.2-19.4 \mu \mathrm{g} / \mathrm{dl}$ ), reduced aldosterone $(<3.7 \mathrm{ng} / \mathrm{dl}$, normal: $3.7-43.7 \mathrm{ng} / \mathrm{dl}) .17-\mathrm{OHP}$ was $>19.2 \mathrm{ng} / \mathrm{ml}$ after a standard dose of adrenocorticotropic hormone stimulation test (ACTH, $\left.250 \mu \mathrm{g} / \mathrm{m}^{2}\right)$. She was diagnosed as NC21OHD due to mild phenotype (see discussion and conclusions) and treated with hydrocortisone $15 \mathrm{mg} / \mathrm{m}^{2} /$ day. At the age of 13 months, she was admitted to the hospital again due to polyuria and polydipsia.

Table 1 Clinical and genetic analysis of a patient with concomitant 21-hydroxylase deficiency and nephrogenic diabetes insipidus

\begin{tabular}{|c|c|c|c|c|c|c|c|c|c|c|c|c|}
\hline & \multirow[t]{2}{*}{ Sex } & \multirow[t]{2}{*}{ Age (year) } & \multirow{2}{*}{$\begin{array}{l}\text { Clinical } \\
\text { presentations }\end{array}$} & \multicolumn{6}{|c|}{ Biochemical tests } & \multirow{2}{*}{$\begin{array}{l}\text { AQP2 } \\
\text { c.439G >A, } \\
\text { p.A147T } \\
\text { in Exon2 }\end{array}$} & \multicolumn{2}{|l|}{ CYP21A2 } \\
\hline & & & & Renin $(\mu \mathrm{lU} / \mathrm{ml})$ & $\begin{array}{l}\text { Aldosterone } \\
(\mathrm{ng} / \mathrm{dl})\end{array}$ & $\begin{array}{l}\text { 17-OHP } \\
(\mathrm{ng} / \mathrm{ml})\end{array}$ & $\begin{array}{l}\text { ACTH } \\
(\mathrm{pg} / \mathrm{ml})\end{array}$ & $\begin{array}{l}\text { Cortisol } \\
(\mu \mathrm{g} / \mathrm{dl})\end{array}$ & $\begin{array}{l}\text { 24-h urine } \\
\text { osmolality }\end{array}$ & & $\begin{array}{l}\text { c. } 1069 \text { C > } \\
\text { T,p.R357W } \\
\text { in Exon8 }\end{array}$ & $\begin{array}{l}\text { c.1360C >T, } \\
\text { p.P454S } \\
\text { in Exon10 }\end{array}$ \\
\hline Father & M & 44 & normal & 64 & 8 & 0.56 & 51.25 & 12.1 & 855 & het & het & het \\
\hline Mother & $\mathrm{F}$ & 40 & $\begin{array}{l}\text { PCOS with } \\
\text { menstrual } \\
\text { irregularity } \\
\text { and mild } \\
\text { hirsutism }\end{array}$ & 86 & $<3.7$ & 2.01 & 25.73 & 8.8 & 737 & het & homo & homo \\
\hline \multirow[t]{2}{*}{ S-1 } & \multirow[t]{2}{*}{$\mathrm{F}$} & \multirow[t]{2}{*}{7} & \multirow{2}{*}{$\begin{array}{l}\text { Clitoromegaly, } \\
\text { polyuria, } \\
\text { polydipsia }\end{array}$} & 115 & $<3.7$ & 6.3 & 10 & 9.6 & 87 & homo & homo & homo \\
\hline & & & & $621^{a}$ & $54^{\mathrm{a}}$ & $0.51^{\mathrm{a}}$ & $5.15^{\mathrm{a}}$ & $22.6^{\mathrm{a}}$ & & & & \\
\hline$S-2$ & $\mathrm{~F}$ & 11 & normal & 47 & $<3.7$ & 1.87 & 34.65 & 9.3 & 473 & wt & homo & homo \\
\hline S-3 & $\mathrm{F}$ & 13 & normal & 161 & 20 & 0.51 & 13.5 & 7.4 & 800 & wt & wt & wt \\
\hline \multicolumn{4}{|c|}{ Normal range } & $5.3-99$ & $3.7-43.7$ & $0.2-0.9$ & $10-60$ & $6.2-19.4$ & $\begin{array}{l}500-800 \\
\mathrm{mOsm} / \mathrm{kg} \\
\text { of water }\end{array}$ & & & \\
\hline
\end{tabular}


Urine density was 1.002 (normal: $1.005-1.030$ ). Hydrochlorothiazide was started at $2 \mathrm{mg} / \mathrm{kg} / \mathrm{d}$ when she was not responded to desmopressin acetate treatment. At the same time, fludrocortisone $\left(100 \mathrm{mcg} / \mathrm{m}^{2} /\right.$ day $)$ was added due to mild hyponatremia (133 mmol/L, normal: $136-145 \mathrm{mmol} /$ $\mathrm{L}$ ) and hyperpotassemia $(5.6 \mathrm{mmol} / \mathrm{L}$, normal 3.5-5.1). Fludrocortisone treatment was discontinued after genetic analysis confirmed the diagnosis. Under the hydrocortisone treatment, the laboratory findings were stable. However, clitoromegaly is persisted and clitoroplasty is planned when she is $9-10$ years old.

Molecular characterization of CYP21A2 mutation. Genomic DNA from peripheral blood leukocytes of patient and family members was isolated using Gentra Blood Kit (Qiagen Corp, CA). To obtain CYP21A2 gene (NM_000500) free from its pseudogene (CYP21A1P) which shares $98 \%$ sequence homology, a differential primer pair was used to amplify the entire $3.5-\mathrm{kb}$ gene containing 10 exons of CYP21A2 (F: 5'-CCCAGGTGG GGGCGGACACTA-3', R: 5'AATTAAGCCTCAAT CCTCTGCAGCG-3') [14]. The long-range PCR was performed using Extensor Hi-Fidelity PCR Master Mix (cat \#AB-0794/B, Thermo Scientific, Waltham, MA, USA). The PCR conditions were $94{ }^{\circ} \mathrm{C}$ for 2 min followed by 30 cycles of amplification $\left(94{ }^{\circ} \mathrm{C}\right.$ for $10 \mathrm{~s}, 60{ }^{\circ} \mathrm{C}$ for $30 \mathrm{~s}$, $68{ }^{\circ} \mathrm{C}$ for $2 \mathrm{~min}$ ) with final extension at $68{ }^{\circ} \mathrm{C}$ for $7 \mathrm{~min}$. The PCR products were re-amplified using the universal primer pairs for each of 10 exons [14]. The resulting PCR products were directly sequenced using an automated $\mathrm{ABI}$ PRISM 3700 sequencer (Foster City, CA, USA) or cloned into a TA vector (Invitrogen, CA, USA). Individual clones were subsequently sequenced. Two previously reported homozygous mutations in the CYP21A2 were identified in the patient: c. $1069 \mathrm{C}>\mathrm{T}$, p.R357W in Exon 8 and c.1360C $>$ T, p.P454S in Exon10 (Fig. 1a), confirming that the patient had 21OHD. Unexpectedly, the same homozygous mutations were also present in her mother and elder sister S-2 who had no clinical symptoms except for menstrual irregularity and mild hirsutism in the mother and precocious puberty in S-2. Lab tests showed low aldosterone and mild increase of 17-OHD (Table 1), but their $\mathrm{Na}$ and $\mathrm{K}$ levels were normal. Father was a heterozygous carrier and elder sister S3 was wild-type. To further substantiate the lab tests, ACTH stimulation test was conducted again in 2017 including all family members. As shown in Table 2, the post stimulation 17-OHP levels were about 10-fold higher in the mother, 7-fold higher in S-2, and 20 -fold higher in patient S-1 when compared to the father or S-3. These data suggest that the mother and S-2 had mild NC21OHD as well. The apparent wild-type genotype in S-3 could not be explained given that the mother was homozygous and father heterozygous for the p.R357W and p.P454S mutants. Genetic mosaicism may contribute to the genotype discordance and phenotype variations among family members: the mother may carry a wild-type CYP21A2 allele which was passed on to her children. Another possibility was that the mother may not be real biological mother of S3. To confirm whether the parents and S-3 were related, we conducted forensic analysis on the family members by multiplex STR analysis using AmpFlSTR Identifiler ${ }^{\circ}$ PCR amplification kit (ABI, Foster City, CA, USA). Capillary electrophoresis and data analysis were carried out by Genetic Analyzer 3130 (ABI, Foster City, CA, USA) and GeneMapper ID software version 3.2 [15]. As shown in Table 3, there was no maternal or paternal exclusion for S-1 and S-3 among 16 STR locus, indicating that both S-1 and S-3 were biological daughters of the parents. To explore the possibility of genetic mosaicism at the CYP21A2 locus, we cloned PCR products of exons 8 and 10 from the mother, S- 1 and her elder sister $\mathrm{S}-2$, and sequenced more than 55 individual clones to determine if we were able to find small number of wild-type clones that could not be detected by direct PCR-sequencing analysis. Indeed, 5 wild-type clones were found among 94 clones sequenced for R357W (5.3\%, 5/94), and 8 wild-type clones was found among 117 clones sequenced for P454S $(6.8 \%, 8 / 117)$ in the mother (Table 4). Although no wild-type clone for P454S was detected in both S-1 and S-2, wild-type clones for R357W were found in S-1 $(3 / 118,2.5 \%)$ and S-2 $(2 / 58,3.4 \%)$. These data suggest that wild-type alleles in the mother's genome (about 6\% in average) may be passed on to S-3, resulting in wild-type genotype. The phenotype variations in $\mathrm{CAH}$ among the mother, S-1 and S-2 likely depend on the abundance of wild-type alleles present in each individual.

Molecular characterization of $A Q P 2$ mutation. Since AVPR2 mutation is frequently found in male patients in $\mathrm{X}$-linked recessive NDI and our patient is female, we screened for $A Q P 2$ mutation first by analyzing all the 4 coding exons and intron-exon boundaries of AQP2 (NM_000486). PCR primers and conditions were described previously [11]. The resulting PCR products were directly sequenced using an automated ABI PRISM 3700 sequencer. A homozygous c.439G >A, p.A147T in exon 2 of $A Q P 2$ was found in the patient (Fig. 1b). Her parents were heterozygous carriers and had no clinical symptoms or biochemical abnormality of NDI, indicating autosomal-recessive transmission. No genotype-phenotype discordance was observed for NDI. The mutation has been described previously to cause significant increase in water permeability [16].

\section{Discussion and conclusions}

In the present study, we have characterized a family with genotype-phenotype discordance in $21 \mathrm{OHD}$ with concomitant NDI in the index patient. Genetic mosaicism at the CYP21A2 locus has been identified and may contribute to the phenotype heterogeneity of $21 \mathrm{OHD}$. 


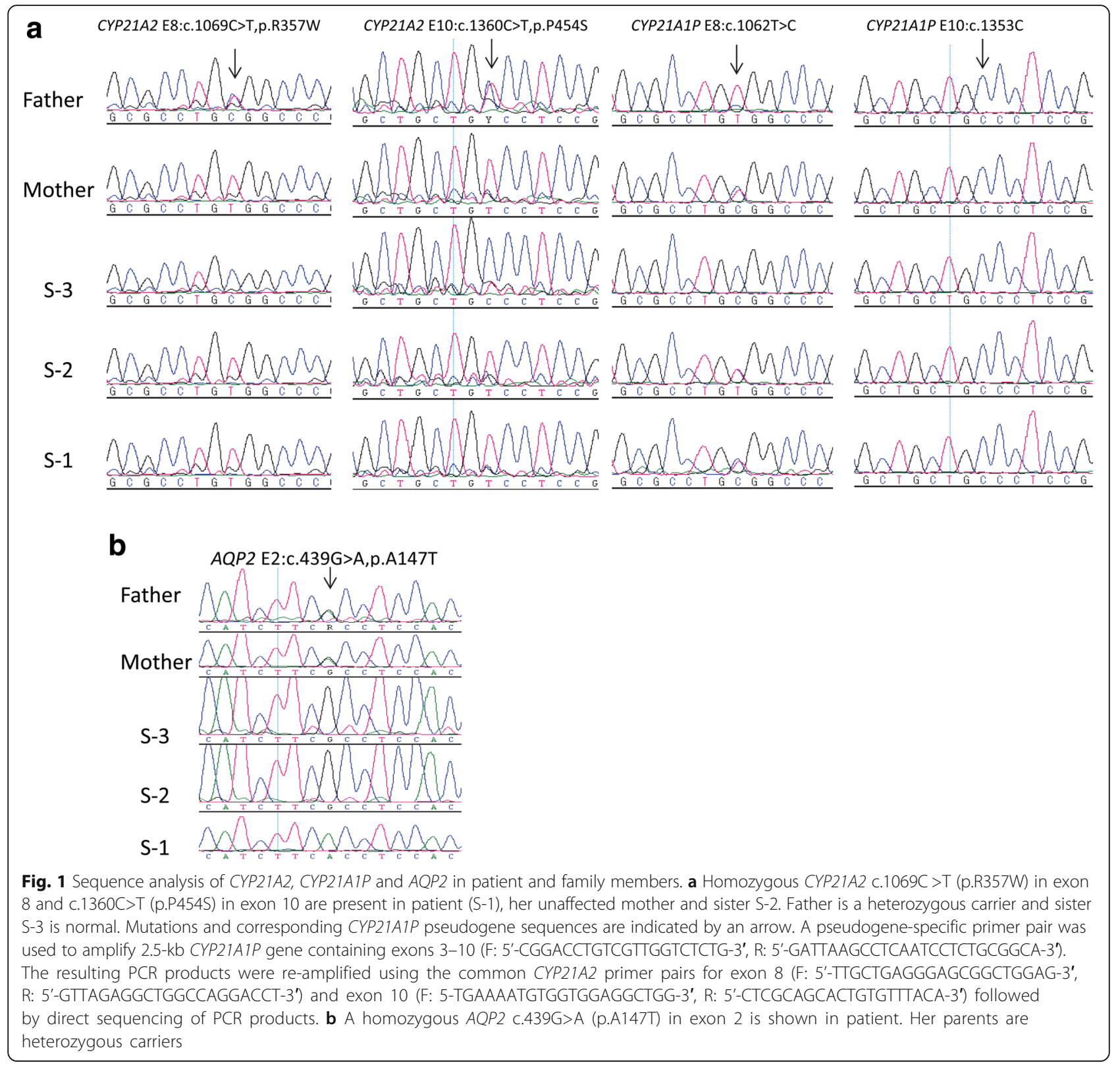

Table 2 ACTH stimulation test among patient and family members

\begin{tabular}{|c|c|c|c|c|c|c|c|c|c|c|c|c|c|c|c|}
\hline & \multicolumn{3}{|c|}{ Father } & \multicolumn{3}{|c|}{ Mother } & \multicolumn{3}{|l|}{$\mathrm{S}-1$} & \multicolumn{3}{|l|}{$\mathrm{S}-2$} & \multicolumn{3}{|l|}{$\mathrm{S}-3$} \\
\hline & $0^{\prime}$ & $30^{\prime}$ & $60^{\prime}$ & $0^{\prime}$ & $30^{\prime}$ & $60^{\prime}$ & $0^{\prime}$ & $30^{\prime}$ & $60^{\prime}$ & $0^{\prime}$ & $30^{\prime}$ & $60^{\prime}$ & $0^{\prime}$ & $30^{\prime}$ & $60^{\prime}$ \\
\hline Glucose & 114 & & & 98 & & & 82 & & & 93 & & & 87 & & \\
\hline $\mathrm{Na}$ & 142 & & & 140 & & & 142 & & & 141 & & & 142 & & \\
\hline K & 4.2 & & & 4.6 & & & 3.9 & & & 5 & & & 4 & & \\
\hline ACTH & 35 & & & 13.7 & & & 1.88 & & & 9.3 & & & 30 & & \\
\hline Cortisol ( $\mu \mathrm{g} / \mathrm{dL})$ & 10.8 & 24.8 & 28.3 & 6.7 & 9.8 & 18 & 5.6 & 4.7 & 8 & 9.2 & 16.2 & 18.3 & 9.4 & 32.2 & 33.3 \\
\hline 17-OHP (ng/ml) & 0.9 & 1.8 & 1.2 & 0.8 & 16.6 & 10.4 & 1.1 & 28 & 33 & 2.1 & 9.7 & 10.8 & 0.9 & 1.2 & 1.62 \\
\hline
\end{tabular}


Table 3 Forensic analysis of family members using 16 STR

\begin{tabular}{|c|c|c|c|c|c|c|c|c|}
\hline \multirow{2}{*}{$\frac{\text { STR }}{\text { D8S1179 }}$} & \multicolumn{2}{|c|}{ Father } & \multicolumn{2}{|c|}{ Mother } & \multicolumn{2}{|l|}{ S-1 } & \multicolumn{2}{|l|}{$\mathrm{S}-3$} \\
\hline & 13 & & 12 & 14 & 12 & 13 & 12 & 13 \\
\hline D21S11 & 28 & 29.2 & 28.2 & 33.2 & 28 & 33.2 & 29.2 & 33.2 \\
\hline D7S820 & 8.2 & 9.2 & 11 & & 9.2 & 11 & 9.2 & 11 \\
\hline CSFIPO & 12 & 13 & 10.2 & 12 & 10.2 & 13 & 12 & \\
\hline D3S1358 & 13 & 15.2 & 14 & & 14 & 15.2 & 13 & 14 \\
\hline TH01 & 5.3 & 8.3 & 8.3 & & 8.3 & & 5.3 & 8.3 \\
\hline D13S317 & 8 & 12 & 8 & 13 & 8 & 13 & 8 & \\
\hline D16S539 & 12 & 12.2 & 11 & & 11 & 12 & 11 & 12.2 \\
\hline D2S1338 & 20 & & 20 & 25 & 20 & 25 & 20 & 25 \\
\hline D19S433 & 12 & 14 & 11 & 11.2 & 11 & 12 & 11.2 & 14 \\
\hline WA & 15 & 15.2 & 13 & 18 & 13 & 15.2 & 13 & 15.2 \\
\hline TPOX & 8 & 9 & 8 & 11 & 9 & 11 & 8 & \\
\hline D18S51 & 12 & 14 & 12 & 14 & 12 & 14 & 14 & \\
\hline AMEL & x & y & $x$ & & $x$ & & $x$ & \\
\hline D5S818 & 9 & 12 & 9 & 11 & 9 & & 9 & \\
\hline FGA & 23 & 24 & 24 & 25 & 24 & 25 & 23 & 25 \\
\hline
\end{tabular}

Our patient presented as a simple virilizing form of $\mathrm{CAH}$ although she had an aldosterone deficiency (increased renin and decreased aldosterone level). Based on published $\mathrm{CAH}$ nomogram on the analysis of 17-OHP levels among $\mathrm{C} 21 \mathrm{OHD}, \mathrm{NC} 21 \mathrm{OHD}$, and carriers, the phenotype of our patient is consistent with NC21OHD [1]. Mutant genotypes of R357W/R357W (previously named R356W) and P454S/P454S (previously named P453S) were found in the patient. Homozygous p.R357W is mainly associated with salt-wasting form of $21 \mathrm{OHD}$ and results in complete loss of its enzymatic activity [8, 17]. P454S is associated with NC21OHD [18]. The apparent genotype-phenotype discordance cannot be explained by the residual enzymatic activity or presence of rare unreported mutations since we have sequenced all the coding exons and intron-exon boundaries of $C Y P 21 A 2$. It is likely that small amount of wild-type CYP21A2 alleles (2.5\%) present in our patient cause phenotype variation and prevent development of salt-wasting form of 21OHD. The normal or milder phenotype seen in the mother and S-2 is probably due to higher percentage of wild-type CYP21A2 alleles in their genome. It is unusual for the patient to carry two homozygous mutant genotypes (R356W and P454S), since majority of CAH patients are compound heterozygotes and NC21OHD phenotype is typically observed in these individuals. This may reflect high degree of consanguinity in the Turkish population.

It has been reported that genotype-phenotype discordance may be due to presence of previously unreported mutations [19] or certain mutations can cause different $\mathrm{CAH}$ phenotypes such as P30L, I172N, and I2G (g.655A/C > G) [8]. In the present study, we have identified genetic mosaicism as an alternative mechanism for genotype-phenotype discordance. Genetic mosaicism refers to the occurrence of two or more populations of cells with different genotypes within an individual. It can be either germline mosaicism developed from a single fertilized egg or somatic mosaicism derived from a postzygotic mutation. Genetic mosaicism should be considered in patients with poor genotype-phenotype correlation. Theoretically, mosaicism should not be transmitted from mother to child because mature eggs are in "all or none" situation (either of wild-type or mutant). Here we demonstrate mosaicism in both mother's and her daughters' (S-1 and S-2) somatic cells. One possible scenario is that the mosaicism found at c.1069 C > T (p.R357W) of $C Y P 21 A 2$ locus is probably due to partial somatic gene conversion of 21-hydroxylase pseudogene CYP21A1P to $C Y P 21 A 2$ during postzygotic mitosis. As shown in Fig. $1 \mathrm{a}$, the corresponding CYP21A1P pseudogene sequence for c.1069C $>$ T (p.R357W) is heterozygous c.1062C and c.1062T alleles present in the mother, S-1 and S-2; and homozygous c.1062C allele in S-3 (father is a homozygous carrier of c.1062T), which may explain the detection of small amount of wild-type c.1069C allele in the mother, S-1 and S-2: partial gene conversion of pseudogene c.1062C allele to wild-type c.1069C allele of $C Y P 21 A 2$. Interestingly, the corresponding CYP21A1P pseudogene sequence for c.1360C $>\mathrm{T}$ (p.P454S) is homozygous c.1353C in all the family members. Although the mother is mosaic for c.1360C locus containing both wild-type c.1360C and mutant c.1360T alleles, only mutant c.1360T allele is detected in S-1 and S-2,

Table 4 Quantification of wild-type and mutant CYP21A2 clones

\begin{tabular}{|c|c|c|c|c|c|c|}
\hline & \multicolumn{2}{|l|}{ Mother } & \multicolumn{2}{|l|}{ S-1 (patient) } & \multicolumn{2}{|l|}{ S-2 } \\
\hline & $\begin{array}{l}\text { c.1069C >T, } \\
\text { p.R357W (Exon 8) }\end{array}$ & $\begin{array}{l}\begin{array}{l}\text { c.1360C >T, } \\
\text { p.P454S (Exon 10) }\end{array}\end{array}$ & $\begin{array}{l}\text { c.1069C > T, } \\
\text { p.R357W (Exon 8) }\end{array}$ & $\begin{array}{l}\text { c.1360C >T, } \\
\text { p.P454S (Exon 10) }\end{array}$ & $\begin{array}{l}\text { c.1069C >T, } \\
\text { p.R357W (Exon 8) }\end{array}$ & $\begin{array}{l}\text { c.1360C >T, } \\
\text { p.P454S (Exon 10) }\end{array}$ \\
\hline Total clones & 94 & 117 & 118 & 55 & 58 & 83 \\
\hline Wt clones & 5 & 8 & 3 & 0 & 2 & 0 \\
\hline Mut clones & 89 & 109 & 115 & 55 & 56 & 83 \\
\hline$\%$ of Wt clones & $5.3 \%$ & $6.8 \%$ & $2.5 \%$ & 0 & $3.4 \%$ & 0 \\
\hline
\end{tabular}


and wild-type c.1360C allele in S-3 (Table 4), which is consistent with the notion that mosaicism could not be transmitted from mother to child.

It is known that sensitivity of Sanger sequencing to detect minor allele or mutant allele is about $20-30 \%$ [20]. To reliably detect minor allele, its frequency should be at least $20 \%$, which explains why the low frequency of wild-type alleles could not be detected by direct PCR-sequencing analysis. The PCR-based sequencing of individual clones or whole-exome sequencing may uncover many more cases of genetic mosaicism.

The patient also developed hyponatremia with polyuria and polydipsia at 13 months old during steroid replacement therapy, probably caused by $A Q P 2$ mutation. The $A Q P 2$ encodes a water channel protein located in the kidney collecting duct principal cells and plays an important role in water homeostasis. The activity of aquaporin 2 (AQP2) is regulated by the antidiuretic hormone vasopressin that determines water permeability in the kidney collecting ducts [21]. Disruption of this physiological mechanism by mutations in either $A V P R 2$ or $A Q P 2$, results in congenital nephrogenic diabetes insipidus (NDI) [22]. More than 278 different $A V P R 2$ and $64 A Q P 2$ mutations have been reported in patients with NDI (The Human Gene Mutation Database, HGMD) [23, 24]. The A147T in AQP2 found in our patient has been reported to cause very low water permeability [25]. Concurrent $A Q P 2$ and CYP21A2 mutations have not been reported in the literature. Given that the patient carry three homozygous mutations: R357W and P454S in CYP21A2 and A147T in $A Q P 2$, it indicates high degree of consanguinity in the patient family or Turkish population in general.

In conclusion, we have characterized a family with genotype-phenotype discordance of $21 \mathrm{OHD}$ with concomitant nephrogenic diabetes insipidus in the index patient. Genetic mosaicism may contribute to the phenotype heterogeneity of $21 \mathrm{OHD}$. The concurrent $A Q P 2$ and $C Y P 21 A 2$ mutations result in $\mathrm{CAH}$ and NDI, respectively.

\section{Abbreviations}

17-OHP: 17-hydroxyprogesterone; 21OHD: 21-hydroxylase deficiency; ACTH: Adrenocorticotropic hormone; C21OHD: classic form of 21OHD; CAH: Congenital adrenal hyperplasia; NC21OHD: non-classic form of 21OHD; NDI: Hereditary nephrogenic diabetes insipidus

\section{Funding}

This study is supported by a KACST grant AT-32-44 (P-L-10-0051) and 13MED1765-20.

\section{Availability of data and materials}

Not applicable. All data and materials are included in the manuscript.

\section{Authors' contributions}

YK participated in the clinical diagnosis and treatments. MZ, RA, and BM contributed to the genetic analysis. YK, YS and MZ drafted the manuscript. DM performed forensic analysis. All of the authors read and approved the final manuscript.

\section{Ethics approval and consent to participate}

Informed consent to participate in the study was obtained from participants or their parent in the case of children under 16. The Ethics Committee of King Faisal Specialist Hospital and Research Centre approved the study (RAC \# 2100005).

\section{Consent for publication}

Consent was obtained from parents to publish patient data.

\section{Competing interests}

The authors declare that they have no competing interests.

\section{Publisher's Note}

Springer Nature remains neutral with regard to jurisdictional claims in published maps and institutional affiliations.

\section{Author details}

${ }^{1}$ Pediatric Endocrinology Division, Ministry of Health, Adana Public Hospitals Association, Adana City Hospital, Adana, Turkey. ${ }^{2}$ Department of Genetics (MBC-03), King Faisal Specialist Hospital and Research Centre, P.O. Box 3354, Riyadh 11211, Saudi Arabia.

Received: 16 January 2018 Accepted: 20 June 2018

Published online: 11 July 2018

References

1. Miller WL. Clinical review 54: genetics, diagnosis, and management of 21hydroxylase deficiency. J Clin Endocrinol Metab. 1994;78(2):241-6.

2. New MI, Wilson RC. Steroid disorders in children: congenital adrenal hyperplasia and apparent mineralocorticoid excess. Proc Natl Acad Sci U S A. 1999;96(22):12790-7.

3. White PC, Speiser PW. Congenital adrenal hyperplasia due to 21-hydroxylase deficiency. Endocr Rev. 2000;21(3):245-91.

4. Hannah-Shmouni F, Chen W, Merke DP. Genetics of congenital adrenal hyperplasia. Endocrinol Metab Clin N Am. 2017;46(2):435-58. https://doi.org/ 10.1016/j.ecl.2017.1001.1008. Epub 2017 Mar 1011

5. Krone N, Braun A, Weinert S, Peter M, Roscher AA, Partsch CJ, Sippell WG. Multiplex minisequencing of the 21-hydroxylase gene as a rapid strategy to confirm congenital adrenal hyperplasia. Clin Chem. 2002;48(6 Pt 1):818-25.

6. New MI. Extensive clinical experience: nonclassical 21-hydroxylase deficiency. J Clin Endocrinol Metab. 2006;91(11):4205-14. Epub 2006 Aug 4215

7. Krone N, Arlt W. Genetics of congenital adrenal hyperplasia. Best Pract Res Clin Endocrinol Metab. 2009;23(2):181-92. https://doi.org/10.1016/j.beem. 2008.1010.1014.

8. New MI, Abraham M, Gonzalez B, Dumic M, Razzaghy-Azar M, Chitayat D, Sun L, Zaidi M, Wilson RC, Yuen T. Genotype-phenotype correlation in 1,507 families with congenital adrenal hyperplasia owing to 21-hydroxylase deficiency. Proc Natl Acad Sci U S A. 2013;110(7):2611-6. https://doi.org/10. 1073/pnas.1300057110. Epub 1300052013 Jan 1300057128

9. Wang R, Yu Y, Ye J, Han L, Qiu W, Zhang H, Liang L, Gong Z, Wang L, Gu X. 21-hydroxylase deficiency-induced congenital adrenal hyperplasia in 230 Chinese patients: Genotype-phenotype correlation and identification of nine novel mutations. Steroids. 2016;108:47-55. https://doi.org/10.1016/j. Steroids2016.1001.1007. Epub 2016 Jan 1021

10. Bichet DG. Nephrogenic diabetes insipidus. Adv Chronic Kidney Dis. 2006; 13(2):96-104.

11. Sasaki S, Chiga M, Kikuchi E, Rai T, Uchida S. Hereditary nephrogenic diabetes insipidus in Japanese patients: analysis of 78 families and report of 22 new mutations in AVPR2 and AQP2. Clin Exp Nephrol. 2013;17(3):338-44. https://doi.org/10.1007/s10157-10012-10726-z. Epub 12012 Nov 10114

12. Garcia Castano A, Perez de Nanclares G, Madariaga L, Aguirre M, Chocron S, Madrid A, Lafita Tejedor FJ, Gil Campos M, Sanchez Del Pozo J, Ruiz Cano R, et al. Novel mutations associated with nephrogenic diabetes insipidus. A clinical-genetic study. Eur J Pediatr. 2015;174(10):1373-85. https://doi.org/10. 1007/s00431-00015-02534-00434. Epub 02015 Apr 00423

13. Mulders SM, Bichet DG, Rijss JP, Kamsteeg EJ, Arthus MF, Lonergan M, Fujiwara M, Morgan K, Leijendekker R, van der Sluijs P, et al. An aquaporin-2 water channel mutant which causes autosomal dominant nephrogenic diabetes insipidus is retained in the Golgi complex. J Clin Invest. 1998; 102(1):57-66. 
14. Lin YC, Lin YC, Liu TC, Chang JG, Lee HH. High-resolution melting curve (HRM) analysis to establish CYP21A2 mutations converted from the CYP21A1P in congenital adrenal hyperplasia. Clin Chim Acta. 2011;412(21-22):1918-23. https:/doi.org/10.1016/j.cca.2011.1906.1033. Epub 2011 Jul 1916

15. Krenke BE, Tereba A, Anderson SJ, Buel E, Culhane S, Finis CJ, Tomsey CS, Zachetti JM, Masibay A, Rabbach DR, et al. Validation of a 16-locus fluorescent multiplex system. J Forensic Sci. 2002;47(4):773-85.

16. Mulders SM, Knoers NV, Van Lieburg AF, Monnens LA, Leumann E, Wuhl E, Schober E, Rijss JP, Van Os CH, Deen PM. New mutations in the AQP2 gene in nephrogenic diabetes insipidus resulting in functional but misrouted water channels. J Am Soc Nephrol. 1997;8(2):242-8.

17. Wang C, Pallan PS, Zhang W, Lei L, Yoshimoto FK, Waterman MR, Egli M, Guengerich FP. Functional analysis of human cytochrome P450 21A2 variants involved in congenital adrenal hyperplasia. J Biol Chem. 2017; 292(26):10767-78. https://doi.org/10.11074/jbc.M10117.792465. Epub 792017 May 792424

18. Owerbach D, Sherman L, Ballard AL, Azziz R. Pro-453 to Ser mutation in CYP21 is associated with nonclassic steroid 21-hydroxylase deficiency. Mol Endocrinol. 1992;6(8):1211-5.

19. Khattab A, Yuen T, Al-Malki S, Yau M, Kazmi D, Sun L, Harbison M, Haider S, Zaidi M, New MI. A rare CYP21A2 mutation in a congenital adrenal hyperplasia kindred displaying genotype-phenotype nonconcordance. Ann N Y Acad Sci. 2016;1364:5-10. https://doi.org/10.1111/nyas.12864. Epub 12015 Aug 12820

20. Zou M, Baitei EY, Alzahrani AS, BinHumaid FS, Alkhafaji D, Al-Rijjal RA, Meyer BF, Shi Y. Concomitant RAS, RET/PTC, or BRAF mutations in advanced stage of papillary thyroid carcinoma. Thyroid. 2014;24(8):1256-66. https://doi.org/ 10.1089/thy.2013.0610. Epub 2014 Jun 1210

21. Jung $\mathrm{HJ}$, Kwon $\mathrm{TH}$. Molecular mechanisms regulating aquaporin-2 in kidney collecting duct. Am J Physiol Renal Physiol. 2016;311(6):F1318-28. https:// doi.org/10.1152/ajprenal.00485.02016. Epub 02016 Oct 00419

22. Bichet DG, Oksche A, Rosenthal W. Congenital nephrogenic diabetes insipidus. J Am Soc Nephrol. 1997:8(12):1951-8.

23. Bichet $D G$, Bockenhauer $D$. Genetic forms of nephrogenic diabetes insipidus (NDI): vasopressin receptor defect (X-linked) and aquaporin defect (autosomal recessive and dominant). Best Pract Res Clin Endocrinol Metab. 2016;30(2):26376. https://doi.org/10.1016/.beem.2016.1002.1010. Epub 2016 Mar 1012

24. Fujiwara TM, Bichet DG. Molecular biology of hereditary diabetes insipidus. J Am Soc Nephrol. 2005;16(10):2836-46. Epub 2005 Aug 2810

25. Shinbo I, Fushimi K, Kasahara M, Yamauchi K, Sasaki S, Marumo F. Functional analysis of aquaporin-2 mutants associated with nephrogenic diabetes insipidus by yeast expression. Am J Phys. 1999;277(5 Pt 2):F734-41.

\section{Ready to submit your research? Choose BMC and benefit from:}

- fast, convenient online submission

- thorough peer review by experienced researchers in your field

- rapid publication on acceptance

- support for research data, including large and complex data types

- gold Open Access which fosters wider collaboration and increased citations - maximum visibility for your research: over $100 \mathrm{M}$ website views per year

At BMC, research is always in progress.

Learn more biomedcentral.com/submissions 